\title{
Obesidade como deficiência: o caso dos judeus
}

\author{
Sander L. Gilman **
}

\section{Resumo}

Atualmente, há uma tendência a encarar a obesidade como uma deficiência física, mas Gilman a adota como um objeto de pesquisa para o estudo da construção cultural do corpo. Neste intuito, reconstitui as representações culturais do corpo obeso a partir do caso dos judeus desde a Bíblia, passando pelo discurso médico e conclui com uma análise da imagem literária do judeu gordo. Em sua análise, o historiador cultural privilegia os aspectos raciais e de gênero implicados na imagem do/a gordo/a.

Palavras-chave: Obesidade, Corpo, Deficiência Física, Judeus, Gênero.

\footnotetext{
* Recebido para publicação em maio de 2004, aceito em julho de 2004. (Tradução: Richard Miskolci; Revisão: Heloisa Buarque de Almeida.)

** Universidade de Illinois, Chicago-Illinois, Estados Unidos. sander34@aol.com
} 
A obesidade como deficiência

Fat as Disability: The Case of Jews

\begin{abstract}
Nowadays, there is a tendency to see fat as a disability. But Gilman adopts obesity as an object for the study of the cultural construction of the body. He reconstitutes the cultural representations of the obese body through the case of the Jews dealing with the Bible, the medical discourse, and the literary image of the fat Jew. Gilman underlines the racial and gender aspects implied in the image of the fat.
\end{abstract}

Key Words: Obesity, Body, Body Disability, Jews, Gender. 
Talvez se possa julgar o quão escorregadio é o conceito de obesidade através do experimento reflexivo que se segue. ${ }^{1}$ Vejamos a questão do que é uma deficiência. Atualmente, a obesidade é considerada uma deficiência, ainda que por um longo tempo ela não tenha sido vista assim. Foi apenas em 1993 que a Comissão Federal para as Condições de Igualdade no Emprego determinou que pessoas "severamente obesas" poderiam pedir proteção através de estatutos federais que coíbem a discriminação contra deficientes. Um caso jurídico que se baseou vagamente nesta regra foi o de Cook versus Rhode Island, um processo impetrado por uma mulher de Rhode Island, Bonnie Cook, que acusou seu Estado de lhe recusar ilegalmente um emprego sob a alegação de uma "deficiência percebida" por causa de seu tamanho.

O Ato para os Americanos com Deficiências (1990) afirma que um dano é uma condição que limita substancialmente as principais atividades da vida. (Definições análogas são usadas na Carta Canadense de Direitos e Liberdades [1994], o Ato Britânico da Discriminação da Deficiência [1995] ou o Ato Sueco sobre apoio e serviços para pessoas com certas deficiências funcionais [1993].) Com certeza, a obesidade limita tais atividades. Os obesos

continuamente encontram várias formas de discriminação, incluindo a exclusão intencional ilegal, os efeitos discriminatórios das barreiras arquitetônicas, de transporte e comunicação, regras e políticas superprotetoras, falha em fazer modificações em equipamentos e práticas existentes, padrões de qualificação e critérios excludentes, segregação e relegação a serviços, atividades, benefícios, empregos ou outras oportunidades inferiores. ${ }^{2}$

1 Chadwick, D. e CARDEW, G. (eds.) The Origins and Consequences of Obesity. New York, John Wiley \& Sons, 1996.

2 Americans with Disabilities Act of 1990. Julho de 1990, seção 2a [law-on-line]. Disponível em: http: | |www.usdoj.gov/crt/ada/pubs/ada.text. 
A obesidade como deficiência

Nos regulamentos promulgados para reforçar este ato, a obesidade mórbida é definida como peso corporal acima de 100\% da norma e causadora de "uma deficiência clara". ${ }^{3}$ Esta linha arbitrária equivale a afirmar que, para ser protegido pelo Ato para os Americanos com Deficiências, o indivíduo não pode apenas ser gordo demais para uma ocupação específica. Num caso, o tribunal concluiu que o "queixoso não pode demonstrar que ele foi visto como deficiente com referência a um emprego específico de sua escolha" ${ }^{4}$ Assim, a questão de definir a obesidade como uma deficiência permanece fluída.

A definição de uma deficiência parece ser mais específica, mesmo que recentemente a Suprema Corte tenha alterado $e$ limitado a sua definição. Em sua Classificação Internacional de Danos, Incapacidades e Deficiências de 1980, a Organização Mundial de Saúde faz uma distinção claramente similar entre dano, incapacidade e deficiência física. Dano é uma anormalidade de estrutura ou função no nível do órgão enquanto incapacidade é a conseqüência funcional deste prejuízo. Uma deficiência física é a conseqüência social do dano e sua resultante incapacidade." Deste modo, danos na capacidade cognitiva ou auditiva podem levar a problemas de comunicação, os quais, por sua vez, resultam em isolamento ou dependência. Tal forma de abordagem funcional (e esta abordagem foi por muito tempo a norma no uso comum e legal americano) parece estar além de qualquer tendência ideológica. Esta muda muito pouco na versão mais recente da idéia de que a deficiência deve ser redefinida em uma escala de "variação humana" que postula as dificuldades dos

3 Equal Employment Opportunity Commission Compliance Manual § 902.2(c)(5).

4 Clemons v. Big Ten Conference, [1997] WL 89227 (N.D. Ill. 1997).

" Nota do tradutor: Os termos em inglês, ainda que possam ser intercambiáveis, ainda são mais precisos do que em português: impairment (dano, prejuízo de um órgão), disability (deficiência, incapacidade) e handicap (deficiência física, desvantagem). 
deficientes mais como resultado da inflexibilidade das instituições sociais do que de suas próprias incapacidades.

No entanto, quando substituímos "obesidade" por "deficiência cognitiva" no modelo funcional há, de forma repentina e evidente, um conjunto de diferenças éticas implicadas em pensar sobre o que uma deficiência pode ser. O que é obesidade? Embora existam conjuntos de definições médicas contemporâneas de obesidade, também é claro que a definição daqueles que são obesos muda de uma cultura para outra com o passar do tempo. A obesidade é mais do que o índice de massa corporal (peso/altura ${ }^{2}$ ), porque até isto muda com o tempo. ${ }^{5}$ Hoje, nos Estados Unidos e no Reino Unido, pessoas com um índice de massa corporal entre $25-30 \mathrm{~kg} / \mathrm{m}^{2}$ são categorizadas como gordas e aquelas com um índice de massa corporal acima de $30 \mathrm{~kg} / \mathrm{m}^{2}$ são rotuladas como obesas. Quando a Pesquisa Nacional de Saúde e Nutrição em 1999 contabilizou um aumento de 54\% na obesidade durante três décadas nos Estados Unidos, usou retrospectivamente o índice de massa corporal de 30 para computar esta imagem. ${ }^{6} \mathrm{O}$ significado do que é gordura e o que é obesidade (suas duas categorias) muda historicamente.

Vamos aplicar os padrões diretos da Organização Mundial de Saúde sobre deficiência ao mundo dos obesos. A obesidade é o produto final de um dano ou é ela mesma um dano? Se ela deve começar com prejuízo de um órgão, qual "órgão" é "prejudicado"? É o próprio corpo? É o sistema digestivo? É o sistema circulatório? Ou é a mente e, portanto, o obeso sofre daquela mais estigmatizante das doenças, a doença mental? A obesidade é uma doença mental resultado de uma personalidade

\footnotetext{
${ }^{5}$ National Institutes of Health. Clinical Guidelines on the Identification, Evaluation, and Treatment of Overweight and Obesity in adults: the Evidence Report. Bethesda, US Department of Health and Human Services, 1998.

${ }^{6}$ FreudenHEIM, Milt. Employers Focus on Weight as Workplace Health Isssue. The New York Times. 06 de setembro de 1999, p.A11.
} 
A obesidade como deficiência

tendente ao vício (em que o vício é a comida)? ${ }^{7} \mathrm{O}$ vício é um sinal de falta de controle? A dependência física é, como no caso da heroína, um vício? O "vício" é um "erro" geneticamente préprogramado no corpo humano, o qual se expressa no desejo psicológico por comida ou a mera incapacidade de saber quando alguém não está mais com fome?

O dano da obesidade é como câncer no pulmão, resultado do consumo voluntário de uma substância perigosa como gordura ou carboidrato? Certamente, a Organização Mundial de Saúde acredita nisso. Após ter lutado contra o consumo de tabaco, busca lançar uma campanha contra os níveis crescentes de obesidade ao persuadir produtores de alimentos industrializados a limitarem as quantias de açúcar adicionado. ${ }^{8}$ Tal tipo de alimento é "viciante" como a nicotina ou meramente um sinal intercambiável para aquelas coisas que todos desejamos, mas a maioria de nós pode limitar? Com certeza, não é possível viver sem comida como alguém poderia viver sem cigarros. A pessoa obesa é deficiente mental ou física? Por outro lado, você pode ser obeso e estável mentalmente? A obesidade é uma doença da "civilização" causada por comida com muita gordura ou muito rica ou muito bem processada? A "cura" será um retorno à "slow food" ou a rejeição da comida em geral? A obesidade se tornou a nova "epidemia" a ser estudada por epidemiologistas e combatida pelas organizações de saúde pública? ${ }^{9}$ Se ela é uma epidemia, ela reflete uma causa única (assim como a SARS) ou é meramente ubíqua? Ou não é doença alguma como comenta um jornalista:

7 Miller, W. R. (ed.) The Addictive Behaviours: Treatment of Alcoholism, Drug Abuse, Smoking and Obesity. Oxford, Pergamon Press, 1980; KASSEL, J. D. e SCHIFFMAN, S. What can Hunger teach us about Drug Craving? A Comparative Analysis of the Two Constructs. Advanced Behavior Research Therapy 14, 1992 , pp.141-167.

8 Killjoy woz here. The Economist, 08 de março de 2003, p.75.

9 MoKdad, A. H.; Serdula, M. K.; Dietz, W.H.; Bowman, B. A.; Marks, J.S.; Koplan, J. P. The Spread of the Obesity Epidemic in the United States 19911998. JAMA, 282:16, October 27, 1999, pp.1519-1522. 
Ser muito gordo não é geralmente visto como uma "doença" real pela maioria das pessoas, até mesmo por aquelas que são gordas, estas mesmas pessoas provavelmente tendem a arranjar uma pílula para reduzir seu peso do que seguir um regime estrito de dieta $e$ exercício. $^{10}$

Como se dieta e exercício fossem a única cura para a miríade de definições de obesidade. A conseqüência social da obesidade é o isolamento ou um lugar central na sociedade? Onde, na escala de "variação humana", você está colocado em um mundo completamente modelado por e para aqueles que não são gordos? A obesidade é exógena ou endógena? No final, você é tratado como um pária social ou como Papai Noel?

Há muitos anos atrás, Tristram Engelhardt, um importante especialista em ética médica, notou que

decidir o que é considerado como saúde requer uma decisão sobre o que conta como um objetivo apropriado para o homem. E para ser aceitável, tal decisão requer lógica clara, fôlego de racionalidade e sensibilidade criativa com respeito a aspectos éticos. Estes são problemas filosóficos tanto quanto problemas médicos. ${ }^{11}$

Eu acrescentaria que estes são problemas tanto culturais, quanto históricos e que a obesidade pode servir como um objeto de estudo elegante para as complexidades de definir os "sadios" e os "doentes". O estudo da obesidade em seus contextos culturais $e$ sociais proporciona uma grande variação de questões interrelacionadas sobre a construção cultural do corpo. O papel que a raça e o gênero exercem é mais uma variável no estudo da representação cultural do corpo obeso.

${ }^{10}$ The Human Genome. The Economist, 01 de julho de 2000, p.7.

${ }^{11}$ EngelhardT JR., H. T. et alii. The Philosophy of Medicine: A New Endeavor. Texas Reports on Biology and Medicine 3, 1973, p.446. 
A obesidade como deficiência

\section{Judeus e gordura}

Historicamente, os judeus dispenderam pouca atenção à representação do corpo masculino obeso. Tal corpo é evocado pela figura bíblica de Eglon, Rei de Moab, o qual oprimiu as crianças de Israel durante dezoito anos. ${ }^{12}$ Seu corpo masculino gordo (ish bari me'od) foi destruído pelo herói canhoto Ehud (Juízes 3:17, 22). (Como o corpo judeu era definido pela circuncisão costumava ser representado pelo corpo masculino.) Até mesmo se descreve como a gordura de Eglon envolveu a lâmina quando ele foi perfurado. Ehud consegue usar sua espada na presença do rei por usá-la do "lado errado", ao menos para destros. Ele é "traiçoeiro e furtivo; talvez a cultura antiga de Israel considerasse essas descrições sinônimas, ao menos estereótipos". ${ }^{13}$ Assim como o rei, seus guardas nem percebem que ele tinha sido estripado até sentirem o cheiro de suas fezes. Este é o caso de um corpo desviante destruindo outro? O corpo masculino gordo talmúdico era um desviante, mas não particularmente perigoso. Ao contrário, ele carrega certa fascinação.

O Talmude até questiona se homens bem gordos, como os rabinos Ishamel ben Yose e Eleazar ben Simeon (fim do século II), poderiam se reproduzir devido às suas barrigas imensas. Aí a figura é a de um corpo que também representa uma verdade oculta. A idéia de que o corpo gordo pensa intuitivamente é um aspecto inerente ao discurso talmúdico. Realmente, em Baba Metzia 83b-85a, tão habilmente explicada por Daniel Boyarin, a lenda do rabino El'azar, o filho de Shim'on, revela que El'azar intuitivamente sabe a verdade por causa de seu corpo gordo. Como um "traidor" romano, ele faz julgamentos que parecem destrutivos, arbitrários ou tolos, mas porque sabe a verdade intuitivamente ele está sempre certo. Ele é um detetive gordo cujas

${ }^{12}$ Preuss, J. Biblical and Talmudic Medicine. New York, Sanhedrin Press, 1978, p.215. (Trad.: Fred Rosner.)

${ }^{13}$ Berquist, J. L. Controlling Corporeality: The Body and the Household in Ancient Israel. New Brunswick, Rutgers University Press, 2002, pp.34-35. 
soluções revelam-se sempre acuradas, ainda que à primeira vista pareçam ser falsas. Um dia, ele prendeu um "certo lavador de roupas" que o insultou. Antes que ele possa perceber o homem é enforcado. Enquanto Rabbi El'azar permanece debaixo do corpo e chora por seu erro, dizem a ele que o homem tinha violado um número de mitzvoth (leis) que, de qualquer forma, o teriam condenado à morte. Quando seu julgamento foi confirmado,

ele colocou suas mãos na barriga e disse: “- Alegrem-se, oh, minhas entranhas, alegrem-se! Se é assim quando vocês estão na dúvida, quando vocês estão certas é melhor ainda. Confio que a podridão e os vermes não prevalecerão sobre vocês".

Mas apesar disto, ele não ficou convencido de sua inerente gorda aptidão. Quando ele está drogado, "cestas de gordura" são estripadas de suas entranhas e colocadas sob o sol de julho. "E ela não fedia. Mas nenhuma gordura fede. Ela fede se tem vasos com sangue vermelho e esta, ainda que tenha veias com sangue vermelho, não fedia". ${ }^{14}$ É a barriga, agora separada do corpo que tem uma vida só sua. Ela representa a habilidade intuitiva desta figura, a qual de outra forma seria suspeita de separar a verdade

${ }^{14}$ apud BoYARIN, Daniel. The Great Fat Massacre: Sex, Death, and the Grotesque Body in the Talmud. In: EILBERG-Schwartz, H. (ed.) People of the Body: Jews and Judaism from an Embodied Perspective. Albany, State University of New York Press, 1992, p.88. Uso a tradução de Boyarin e não a contemporânea. A tradução de Soncino segue: "Regozige-se, meu coração! Se em questões em que vós [o coração] encontra-se em dúvida são assim, quão mais naquelas em que vós estais certo! Tenho certeza de que nem vermes nem decadência terão poder sobre vós.' Apesar disso, sua consciência não o deixou em paz. Imediatamente ele recebeu um golpe de sono, foi levado a uma câmara de mármore e cestos de gordura foram removidos dele e colocados ao sol durante Tammuz e Ab e mesmo assim ela não apodreceu. Mas nenhuma gordura apodrece! - [Verdade,] nenhuma gordura apodrece; no entanto, se ela contém traços vermelhos, sim. Mas aqui, ainda que ela contivesse traços vermelhos, ela não apodreceu. Logo após ele aplicou a si mesmo o verso: Minha carne também deverá duelar em segurança". 
da mentira. A intuição é, literalmente, um sentimento que vem de dentro.

Mas as atitudes judaicas com relação à obesidade foram claramente definidas pelo modelo de falta de autocontrole. De forma distinta à enumeração teológica cristã muito posterior dos "Sete Pecados Capitais", a glutonia não foi incluída em nenhuma das versões dos Dez Mandamentos na Bíblia hebraica. Claro que a glutonia não é louvada entre os judeus. Ela pode ser vista como um sinal de fraqueza humana como em Provérbios 23:20-21:

Não fique entre bebedores de vinho; entre comedores de carne desordeiros; pois o bêbedo e o glutão cairão na pobreza e a preguiça cobrirá um homem com trapos. [Ou de violação da ordem humana em Deuterômimo 21:20] Este nosso filho é teimoso e rebelde, não obedece nossa voz; ele é um glutão e um bêbado; e todos os homens desta cidade o apedrejarão e ele morrerá.

É apenas com a condenação paulina da carne que a dessacralização do "templo do Espírito Santo" através da obesidade mancha a alma que habita o corpo obeso. O homem gordo é incapaz de se tornar honrado. (I Corinthians 6:19: "O quê? Não sabes que teu corpo é o templo do Espírito Santo que está em ti, que tendes de Deus e que não é teu?")

A obesidade entre os judeus, vivendo nas diásporas cristã e muçulmana, era um sinal de falta de autodisciplina não apropriada para um homem de verdade, um verdadeiro estudioso, e podia ser punida. ${ }^{15} \mathrm{Na}$ obra clássica sobre dietética do filósofo-médico ibérico do século XII Maimonides, o Regimes da Saúde, não há o menor sentimento de que a obesidade era um problema moral ou mesmo médico (ao menos para os soberanos para os quais ele escreveu), porém a manifestação sexual

${ }^{15}$ KotTeK, S. S. On Health and Obesity in Talmudic and Midrashic Lore. Israel Journal of Medical Sciences 32, 1996, pp.509-10. 
excessiva era. ${ }^{16}$ No entanto, a obesidade ainda era vista como um assunto importante da saúde com repercussões sobre o corpo do indivíduo. Maimonides tratava a condição de "velhos obesos" com medicação, exercício, massagem e banhos. ${ }^{17}$ Sua obra proporciona uma síntese da medicina galênica e da obra do médico árabe Ibn Sina (Avicenna, 980-1037), cujo Kitah al-Quanun ou $O$ Cânone inclui uma discussão detalhada da obesidade em seu quarto livro.

É apenas na modernidade, com a transformação secular da obesidade de uma marca de pecado para um sinal de doença, que o corpo dos judeus vem a representar todo o potencial para a doença e a decadência associada ao corpo moderno do menino gordo. Isto se dá sob a luz da compreensão geral do estereótipo "judeu" tanto na cristandade quanto no Islã como a antítese do saudável, verdadeiro crente. As doenças atribuídas à diferença inerente do corpo "judeu" (agora o corpo doente per se) tornamse o teste para a diferença "judia". Em tal sistema é sempre útil ter sinais e sintomas visíveis para associar à diferença clara dos "judeus".

Na moderna medicina ocidental, havia uma preocupação com a afirmada predisposição judaica para diabetes. A prática do século XIX de rotular os judeus como raça "diabética" era uma forma de os rotular como inferiores. No outono de 1888, o neurologista parisiense Martin Charcot descreveu para Sigmund Freud a predisposição dos judeus para formas específicas de doenças como a diabetes e como o "diagnóstico é fácil", já que a doença era causada pela endogamia deles. O "incesto" judeu deixara sua marca no corpo judeu na forma da diabetes, assim

${ }^{16}$ MAIMONIDES. Das diätetische Sendschreiben des Maimonides (Rambam) an den Sultan Saladin. Viena, Braumüller und Seidel, 1843 (Editado e traduzido por D. Winternitz). Comparar com Rosner, F. The Medical Legacy of Moses Maimonides. Hoboken, KTAV, 1998, p.58.

${ }^{17}$ MAIMONIDES. Medical Wrtings: the Art of Cure - Extracts from Galen. Vol. 1, Haifa, Maimonides Research Institute, 1992, pp.175-76. (Editado e traduzido por U. S. Barzel.) 
como em sua alma. (É indicativa de sua atitude depreciativa com relação aos judeus o fato de que a carta de Charcot para Freud usava o termo vulgar "juif" ao invés do mais educado "Israélite" ou do mais científico "sémite".) ${ }^{18}$ No entanto, há visões posteriores sobre porque os judeus são predispostos a esta doença. O eugenista britânico George Pitt-Rivers atribuiu a taxa crescente de diabetes entre judeus à "natureza passional de seus temperamentos". Ele notou que por volta da década de 1920 a diabetes era chamada comumente de uma "doença judaica" ${ }^{19}$

Novamente, a obesidade, inerente ao corpo do judeu (e à sua alma) era vista como a causa da doença.

[As] raças orientais, enervadas pelo clima, costumes $e$ superalimentação abundante em gorduras, açúcar $e$ massas progredirão inevitavelmente na criação de gerações gordas, criando um solo extremamente favorável para a obesidade. $^{20}$

Até mesmo na Diáspora o pressuposto é que o judeu é diabético por causa de sua predisposição para a gordura:

Todos os observadores têm concordado que os judeus têm uma tendência particular a se tornarem diabéticos... Uma pessoa que pertence às classes mais ricas nas cidades normalmente come demais, gasta grande parte de seu tempo dentro de casa, pratica pouco exercício físico $e$ sobrecarrega seu sistema nervoso na busca por conhecimento, negócios ou prazer... Tal descrição é uma avaliação acurada do judeu rico que ascende facilmente

\footnotetext{
${ }^{18}$ Gelfand, T. "Mon Cher Docteur Freud": Charcot's Unpublished Correspondence to Freud, 1888-1893. Bulletin of the History of Medicine, 62, p.574.

${ }^{19}$ Pitt-Rivers, G. H. L. F. The Clash of Culture and the Contact of Races. London, Routledge, 1927, p.82.

${ }^{20}$ Frumusan, J. The Cure of Obesity. London, John Bale, 1930, p.9. (Trad.: E. A. Wood.)
} 
através de sua habilidade mental superior para uma posição social confortável e notoriamente evita todo tipo de exercício físico. ${ }^{21}$ de vida:

Os judeus herdaram sua tendência à gordura de seu estilo

Pode a ingestão excessiva de comida continuada durante muitas gerações criar um grande apetite na prole $e$, alternativamente, pode isto causar uma fraqueza funcional de seu mecanismo regulador de peso? [pergunta W. F. Christie. E responde] Tome, por exemplo, os hebreus, dispersos pelos confins da Terra. Provavelmente nenhuma raça no mundo tem uma tendência tão aparente para se tornar robusta depois da puberdade ou é mais freqüentemente citada como um exemplo racial de obesidade. Também é provável que nenhuma outra nação esteja aprisionada aos seus hábitos e costumes raciais de maneira tão generalizada. [Elliot] Joslin diz sobre a atual geração de judeus: "A alimentação excessiva começa na infância e dura até à velhice". A herança de grandes apetites e mecanismos de regulação para a diminuição do peso pode existir, ainda que eles não mostrem sinais do último; ao passo que a herança de hábitos que levam à obesidade é certa. ${ }^{22}$

Aqui a "natureza" prevalece sobre a "cultura" até mesmo entre judeus emancipados.

Assim, os judeus herdam os padrões compulsivos de alimentação de seus ancestrais e, por isso, já são gordos desde criança. A obesidade e a diabetes deles são um reflexo de suas tradições higiênicas ruins, precisamente o oposto do que

${ }^{21}$ SAUNDBY, R. Diabetes mellitus. In: Allbutt, T. C. (ed.) A System of Medicine. London, Macmillan, 1897, pp.197-99.

${ }^{22}$ CHRISTIE, W. F. Obesity: A Practical handbook for Physicians. London, William Heinemann, 1937, p.31. 
A obesidade como deficiência

defendiam os reformadores judeus do século XIX, os quais viam o judaísmo como a religião racional da higiene. De fato, o judeu "oriental" apresenta o pior caso para esta linha de argumentação. Max Oertel, talvez a autoridade em obesidade mais citada no início do século $\mathrm{XX}$, afirma que

as judias de Tunis, quando mal alcançam dez anos, são sistematicamente engordadas ao serem confinadas em quartos escuros $e$ alimentadas com artigos farináceos $e$ carne de cachorro até que, no curso de uns poucos meses, elas parecem blocos de gordura sem forma. ${ }^{23}$

Aqui a fantasia sobre o corpo "oriental" no Ocidente é intensificada pelos judeus alimentando suas filhas com comida não kosher. Os judeus são inerentemente hipócritas, argumentava a literatura do século XIX que criticava o abate ritual. Na verdade, eles comerão de tudo e qualquer coisa, ainda que aleguem que sua prática religiosa os impede de comer algo que não seja kosher. A obesidade aqui se torna um sinal dessa hipocrisia.

Escondido dentro de um corpo de judeu moderno, aculturado, está um judeu racialmente definido cujo corpo se trai. Desta forma, William-Frédéric Edwards, um médico, afirmou em 1829 que as raças permaneciam constantes por todo o mundo. ${ }^{24} \mathrm{~A}$ prova de Edwards para isto era a estabilidade dos judeus em todo o planeta.(129) O médico escocês Robert Knox, amigo de Edwards, trouxe como prova o "fato" de que os retratos de judeus nas tumbas egípcias pareciam com os judeus da Londres contemporânea!(130) Com certeza, Oscar Wilde estava certo, décadas depois, quando afirmou que a natureza copia a arte ao

${ }^{23}$ Oertel, M. J. Obesity. In: Stedman, T. J. (ed.) Twentieth Century Practice. 20 vols., London, Sampson Low, Marston and Co., 1895-1900, vol. 2 - Nutritive Disorders -, pp.647-48.

${ }^{24}$ Todas as citações de STAUM, M. S. Labeling People: French Scholars on Society, Race, and Empire 1815-1848. Montreal and Kingston, McGill-Queens University Press, 2003. 
invés de a arte copiar a natureza. A realidade do mundo espelhava a fantasia de seus observadores. As fantasias sobre o corpo judeu demandavam tais argumentos de continuidade. Em 1841, Hubert Lauvergne, um seguidor do frenologista Franz Joseph Gall, afirmou que os gregos contemporâneos traziam a face orgulhosa e o crânio da Grécia antiga enquanto a "imutabilidade do tipo judeu" provava sua degeneração.(59) Um sinal disso era o corpo obeso e sua predisposição para a diabetes.

Desde o século XIX, a diabetes tem sido vista como uma doença dos obesos e, em um estranho conjunto de associações, o judeu foi considerado como obeso devido a um aparente aumento de diabetes entre judeus. De acordo com um especialista da virada do século, especialmente judeus ricos (homens) eram gordos $^{25}$, mas ao invés de defender uma herança metabólica inata, ele afirmou que isto se devia a uma dieta pobre entre os ricos - comida muito gordurosa e álcool, outro estereótipo do judeu. Porém, o outro lado da moeda está muito presente.

Estudiosos judeus reagiram de uma maneira não menos sangüínea. No ensaio sobre diabetes da Enciclopédia Judaica da virada do século, escrito pelos respeitados estudiosos da doença dos judeus, Joseph Jacobs (britânico) e Maurice Fishberg (norteamericano), há uma rejeição clara da premissa de que judeus tinham tendência à diabetes por razões "raciais". ${ }^{26}$ Eles afirmam categoricamente que: "Também já foi mostrado que a diabetes não é uma doença racial dos judeus".(554) Para eles, ela é uma doença da "civilização", não dos judeus. Assim que os judeus se tornaram emancipados e secularizados começaram a ter todas as doenças das culturas às quais eles parecem se adaptar, da mesma forma que a dicotomia da propensão ou imunidade judaica contra a diabetes.

\footnotetext{
${ }^{25}$ von NoORDEn, C. Die Fettsucht. Wien, Alfred Hölder, 1910, p.63.

${ }^{26}$ JACOBS, J. e FISHBERG, M. Diabetes Mellitus apud The Jewish Encyclopedia. 12 vols., New York, Funk \& Wagnalls, 1905-1926, vol. 4, pp.553-56.
} 
A obesidade como deficiência

Ambas as visões, [eles afirmam] (1) de que os judeus sofrem mais freqüentemente de diabetes do que quaisquer outras raças $e$ (2) de que eles não são afetados com mais freqüência são provavelmente bem fundamentadas. Tratase apenas de uma questão da nacionalidade dos judeus: os judeus na Alemanha, por exemplo, com certeza são mais diabéticos do que na Rússia, Inglaterra e França e a diferença de opinião entre médicos experientes deve-se simplesmente ao fato de que eles normalmente são negligentes ao considerar a questão do local de nascimento dos judeus. Nos Estados Unidos, onde os judeus chegaram de vários países, a diabetes é encontrada de forma extremamente freqüente entre os judeus alemães $e$ húngaros, enquanto entre os judeus russos ela não é mais, talvez seja até mesmo menos, freqüente do que entre outras raças.(555)

A diabetes é uma doença que se torna evidente entre judeus assim que eles mudam de uma cultura para outra, seja de um mundo em que eles sentem fazer parte da identidade nacional (Alemanha) ou de um em que eles são alienados (Rússia).

Jacobs e Fishberg são forçados a confrontar outra teoria para o aparecimento da diabetes entre os judeus. $O$ antisemitismo, no final do século XIX, via os judeus como um povo essencialmente "doente" $e$ atribuía as origens da doença ao incesto/endogamia, rotulada, no caso dos judeus, como uma "consciência da espécie". Enquanto a doença que dominava o discurso da ciência anti-semita era a loucura (e Jacobs e Fishberg confrontam esta afirmação em sua obra e em toda a Enciclopédia Judaica), a diabetes também era atribuída à endogamia judaica. Sua origem também estava nos casamentos "perigosos" dos judeus, ou seja, em sua recusa em casar com pessoas de fora do grupo. Estes casamentos foram rotulados como atividade criminosa mesmo quando tal "endogamia" não era consangüínea. Em termos históricos, escritores como Houston Stewart Chamberlain podiam comentar sobre a origem dos judeus e suas 
"expressões simples e frescas nas genealogias da Bíblia, de acordo com as quais algumas dessas raças devem sua origem ao incesto enquanto outras descendem de prostitutas". ${ }^{27}$

A polêmica de Chamberlain também aparece na época sob o disfarce de descrição etnológica. Não só os judeus são descritos como permitindo historicamente o incesto entre irmãos (Geschwisterehe), mas também seus praticantes, mesmo depois de terem afirmado que o proibiam. O resultado patológico de tais práticas abertas ou ocultas é a maturidade sexual prematura. ${ }^{28}$ As várias ligações entre formas desviantes de sexualidade, como o incesto entre irmãos e a prostituição (a etiologia final da doença mental numa era de fobia com relação à sífilis) colocavam os judeus e suas práticas de casamento no centro da preocupação "biológica". Havia, ainda, um raciocínio econômico oculto nesta discussão, pois, ao se recusarem a casar na sociedade em geral, os judeus pareciam sinalizar que eram uma entidade econômica que vivia fora da sociedade comum e não contribuía para ela. A "endogamia" era vista como a origem da hegemonia econômica dos judeus e era tão venenosa quanto as suas atividades sexuais.

Na literatura sobre diabetes, casamentos consangüíneos são apresentados como mais freqüentes entre os judeus do que entre a maioria das outras raças. A prática judaica, mais do que qualquer outra coisa, está no centro da diabetes, de acordo com um grupo de estudiosos.

Os judeus são filhos e netos de moradores de cidades [diz Bouchard]. A longo prazo, as influências hereditárias desfavoráveis não são retificadas pelo casamento freqüente entre a população urbana e a rural, como é o caso com o resto da população. Os judeus casam exclusivamente entre si; primeiro, primos do lado paterno ou materno não

${ }^{27}$ Chamberlain, H. S. Foundations of the Nineteenth Century. London, John Lane/The Bodley Head, 1913, volume 1, p.366. (Trad.: John Lees.)

${ }^{28}$ GÜNTHER, H. F. K. Rassenkunde des jüdischen Volkes. München, J. F. Lehmann, 1930, p.134. 
A obesidade como deficiência

encontram barreiras para casar e imediatamente ao nascer o jovem israelita recebe as influências desfavoráveis acumuladas (hereditárias), que depois desenvolve durante sua vida e que tendem a doenças que são geradas pela nutrição irregular, particularmente a diabetes.(556)

O que os autores negam fortemente. Apesar disso, é claro, no ensaio conjunto de Jacobs e Fishberg sobre "diátese" ("predisposição para certas formas de doença") na Enciclopédia Judaica, que eles também rejeitam a obesidade como causa da diabetes. Os judeus podem sofrer de "artrite", rubrica que

engloba um certo grupo de doenças, geralmente devido a distúrbios do metabolismo normal, que se manifestam primariamente como reumatismo crônico e gota, mas que também incluem outros processos mórbidos tais como a diabetes, pedras na vesícula, pedras nos rins, obesidade e algumas doenças de pele. [Mas estas] não são raciais no sentido pleno da palavra. Na maioria dos casos elas se devem ao modo de vida, ao fato de que judeus são quase exclusivamente habitantes das cidades $e$ às ansiedades de suas ocupações. ${ }^{29}$

Para eles, a obesidade permanece um produto da civilização $e$ a diabetes é uma de suas manifestações.

No começo do século XX, cientistas começaram a explorar a relação entre a predisposição dos judeus para a diabetes $e$ a relação que existiria entre diabetes e obesidade. Em 1926, um médico notou que

dado que um em cada doze cristãos obesos desenvolvem diabetes não mais do que um em cada oito judeus obesos a desenvolvem. Isto, é sugerido, deve ser explicado pelo fato de que um hebreu gordo é sempre mais gordo do que um

${ }^{29}$ JACOBS, J. e FISHBERG, M. Diathesis. The Jewish Encyclopedia. Op. cit., p.574. 
Sander L. Gilman

cristão gordo e que é a maior obesidade que determina a preponderância semita na diabetes. ${ }^{30}$

O pressuposto da ligação entre obesidade e a raça "oriental" começa a rondar as discussões sobre o significado da gordura. ${ }^{31}$ Quando W. H. Sheldon desenvolveu seus "tipos somáticos", na década de 1940, observou que judeus mostram um exagero em cada um de seus tipos corporais. Assim, judeus gordos são, de alguma forma, mais gordos do que gordos não-judeus. ${ }^{32}$ Estudos mais recentes de judeus obesos atentam para os padrões comportamentais complexos que ocorrem quando demandas religiosas pelo jejum e a predisposição psicológica dos obesos entram em conflito. ${ }^{33}$

Hoje, a diabetes geralmente não é considerada uma doença judaica. A pesquisa agora segue a assim chamada hipótese genotípica frugal sugerida em 1964. De forma resumida, tem sido observado que quando camundongos são transferidos de um meio hostil para um meio benigno, eles ganham peso e ficam hiperglicêmicos. Quando se avalia desta forma a primeira geração de grupos de imigrantes para os Estados Unidos no final do século $\mathrm{XIX}$, ou em Israel hoje, há uma taxa substancialmente mais alta de diabetes. Os grupos iniciais, como os lemenitas que imigraram para Israel de um meio-ambiente hostil, mostraram um índice extremamente baixo de diabetes quando chegaram em Israel. No

${ }^{30}$ Williams, L. Obesity. London, Humphrey Milford/Oxford University Press, 1926, p.53.

${ }^{31}$ Veja Leray, J. Embonpoint et Obésité. Paris, Masson et cie, 1931, pp.11-12; CHRISTIE,W. F. Surplus Fat and How to Reduce it. London, William Heinemann, 1927, que começa com uma longa discussão da predisposição racial à gordura, pp.1-8.

32 Sheldon, W. H.; Stevens, S. S. e Tucker, W. B. The Varieties of Human Physique. New York, Harper \& Brothers, 1940, p.221.

${ }^{33}$ Sobre judeus gordos e jejuadores, veja Who fasts on Yom Kippur?. In: SCHACHTER, Stanley. Emotion, Obesity, and Crime. New York, Academic Press, 1971, pp.124-34, capítulo X. 
A obesidade como deficiência

entanto, este índice disparou logo depois de um curto tempo de vida em seu novo meio. Portanto, a diabetes e a obesidade parecem ser um índice de uma falha em se adaptar rapidamente a novos ambientes. ${ }^{34}$

Ainda assim, a obesidade é imaginada como um assunto judaico. No entanto, hoje, com uma mudança na questão de gênero, já que, desde a década de 1910 até o presente, a "gordura" ter se tornado uma questão para as mulheres ao invés de o foco ser na raça e na masculinidade. O colunista David Margolis, em The Jewish Journal of Greater Los Angeles, 2002, observa que:

Muita gente também considera a gordura um assunto judaico. De acordo com uma pesquisa recente na região da cidade de Nova York, famílias judias consomem "quase o dobro" da quantia de bolos e donuts que famílias nãojudias, e mais do que duas vezes refrigerante diet e queijo cottage. Um profissional da indústria dos distúrbios alimentares defende que os judeus tendem a escolher a comida ao invés de vícios em outras substâncias. A comida é apenas outra droga, acima de tudo, a mais barata, a mais fácil de encontrar, a substância que altera o humor mais aceita socialmente. Será apenas uma coincidência que os Alcoólicos Anônimos tenha sido fundado por dois homens cristãos, enquanto os Comedores em Excesso Anônimos foi fundado por duas mulheres judias? ${ }^{35}$

A imagem do judeu superalimentado, central para a cultura que precisava ver a doença oriental da diabetes como um aspecto essencial da alma judia corrupta, agora tem um lugar na cultura

${ }^{34}$ Goodman, R. M. Genetic Disorders among the Jewish People. Baltimore, Johns Hopkins, 1979, pp.334-41 apud SCHMIDT-NIELSEN, K. et alli. Diabetes mellitus in the sand rat induced by standard laboratory diets. Science 143, 1964, p.689. Consulte também Mourant, A. E.; KoPEC, A. C.; DomaniEWSKA-SOBCZAK, K. The Genetics of the Jews. Oxford, Clarendon Press, 1978.

${ }^{35}$ www.davidmargolis.com/journalism_fat.html. 
popular americana sobre o corpo judeu. Ele é também transformado no corpo da mulher judia, assim como a "gordura" nos Estados Unidos "é uma questão feminista". ${ }^{36}$

A gordura é uma questão judaica apenas na medida em que, como parece ser no exemplo de Los Angeles, ser judeu é visto como uma categoria étnica ao invés de religiosa. Em uma série de ensaios, Kenneth Ferraro, sociólogo e médico, atentou para o corolário entre prática religiosa e obesidade, usando dados desde 1986. Em seus estudos, estava claro que a "obesidade é associada a níveis mais altos de religiosidade".(232) A obesidade predominava naquelas partes dos Estados Unidos que tinham o mais alto nível de prática religiosa (e pode-se acrescentar de pobreza). ${ }^{37}$ Os batistas do Sul em 1998 eram os mais gordos das denominações cristãs, católicos romanos estavam no meio da escala $e$ judeus (e outros não-cristãos) formavam a extremidade magra desta amostra. Mas ser judeu aqui se correlaciona com ser membro de congregações, e com identidade e renda de classe média. Ferraro conclui seu artigo de 1998 observando que comida e religião proporcionam "alguns dos poucos prazeres acessíveis para populações que são excluídas econômica e politicamente". (236) Marx estava certo, a religião (e aqui podemos acrescentar a comida) é o ópio do povo. Evidentemente, quando judeus são considerados como um grupo religioso ao invés de uma etnia, eles são suficientemente magros.

\footnotetext{
${ }^{36}$ Veja OrBACH, S. Fat is a Feminist Issue: the Anti-Diet Guide to Permanent Weight Loss. New York, Berkley Books, 1979.

${ }^{37}$ FerRaro, K. F. Firm Believers? Religion, Body Weight, and Well-being. Review of Religious Research 39, 1998, pp.224-244; e Does Religion Influence Adult Health? Journal for the Scientific Study of Religion 30, 1991, pp.193-202; KoCH, J. Religion and Health among Black and White Adults. Journal for the Scientific Study of Religion 33, 1994, pp.362-75.
} 
A obesidade como deficiência

\section{A imagem literária do judeu gordo}

As implicações culturais de ver a obesidade como um problema "judeu" (ou ao menos como um problema dos judeus) tem seu eco nas primeiras tentativas de fornecer um texto literário judeu secular, autocrítico. A imagem do companheiro gordo na literatura moderna, seguindo o icônico homem gordo de Cervantes, mostra como Sancho Pança se torna um modelo para a associação posterior entre a obesidade e um tipo de efeminamento. $\mathrm{O}$ homem gordo nesta continuação judaica da figura de Sancho Pança realmente reflete a confusão de gênero presente nos debates do século XIX e a identificação do judeu "exótico" como o indivíduo sob o risco do estigma social da obesidade. No primeiro romance iŕdiche moderno, As Viagens e Aventuras de Benjamin Terceiro (1885) de Mendele Mosher Seforim, o par de protagonistas magro e gordo, tão bem conhecido das ficções (Quixote e Sancho Pança) assim como das narrativas da adversidade superada é repetido com variações cheias de significado. ${ }^{38}$ Aqui a figura obesa é claramente definida com atributos abertamente atribuídos ao feminino na cultura popular iídiche. O Sancho Pança de Mendele, Senderel, é "de mente simples, modesto"(37) e freqüentemente é o mote das piadas na sinagoga. Sua esposa o consola e ele assume os deveres dela na cozinha. Realmente, ele é chamado Senderel "die Yiddine", a dona-de-casa.(39) Nosso Quixote, Benjamin, "sempre achou um prazer conversar com ele. É bem possível que Benjamin tenha levado em consideração a falta de resistência de Senderel, que tenderia a concordar com seu plano".(39) Como Quixote, Benjamin convence Senderel a deixar sua família e seguir com ele numa aventura. Quando eles vão embora, Senderel está vestido com "uma saia de algodão cru e um chapéu de mulher".(48) O

${ }^{38}$ MENDELE, Mocher Seforim. The Travels and Adventures of Benjamin the Third. New York, Schocken, 1949. (Trad.: M. Spiegel). Veja MiRON, D. A Traveler Disguised: The Rise Of Modern Yiddish Fiction in The Nineteenth Century. Syracuse, Syracuse University Press, 1996. 
par do gordo e do magro de Cervantes infiltrou-se na cultura de tal modo que, na época de Mendele, não há mais nem mesmo a necessidade de evocar o tipo corporal. Supõe-se que Benjamin tem o corpo como o do protagonista de Cervantes e que seu Sancho Pança é de novo o "Sr. Barriga". Mas, como a releitura do corpo judeu obeso na literatura sobre diabetes da época, esta imagem do homem feminino tem ressonância contemporânea.

Aqui o leitor é apresentado à imagem do judeu como mulher. A hipótese da cultura do século XIX era a de que os judeus eram efeminados. Eles não eram mulheres, mas um tipo de "terceiro sexo", nem homem nem mulher. A imagem do judeu foi "feminizada" até mesmo na obra de cientistas judeus do período. Ao aceitar a visão de que os judeus eram uma única raça em 1904, o médico judeu Heinrich Singer, de Elberfeld, comenta que "em geral é claro ao examinar o corpo do judeu que ele mais se aproxima do tipo corporal da mulher". ${ }^{39}$ Hans Gross, famoso criminologista de Praga (e pai do psicanalista Otto Gross), pôde tranqüilamente comentar sobre a "mão pequena, feminina, do judeu" ${ }^{40}$ Estas visões médicas ecoavam uma visão antropológica mais antiga. Em meados dos oitocentos, o etnólogo judeu (e rabino), Adolph Jellinek afirmou diretamente que:

no exame de várias raças é claro que algumas são mais masculinas, outras mais femininas. Os judeus pertencem às últimas, como uma daquelas tribos que são ao mesmo tempo mais femininas e vieram a representar (repräsentieren) o feminino entre outros povos. Uma justaposição do judeu com a mulher persuadirão o leitor da verdade da tese etnográfica. [A prova fisiológica de Jellinek é a voz do judeu] Ainda que no entanto eu desaprove a comparação fisiológica, deixe-me notar que vozes graves

39 SINGER, H. Allgemeine und spezielle Krankheitslehre der Juden. Leipzig, Benno Konegen, 1904, p.9.

${ }^{40}$ Gross, H. Kriminal-Psychologie. Leipzig, F.C.W. Vogel, 1905, p.121. 
A obesidade como deficiência

são muito mais raras do que as de barítono entre os judeus" ${ }^{11}$

A associação da imagem do judeu (leia aqui: judeu homem) com a da mulher (incluindo a mulher judia) é uma das imagens mais poderosas a serem incluídas nos argumentos sobre raça. E é a imagem da mulher gorda, a oriental, do século XIX tardio que assombra o romance de Mendele. Uma obra escrita para criticar as práticas e atitudes do Leste Europeu do ponto de vista do Iluminismo judaico, o corpo gordo de Senderle reflete a crítica complexa do pensamento de Haskalah sobre o impacto do gueto no corpo judeu. Aqui é muito evidente a aproximação da questão do judeu diabético refletindo a natureza do meio dele (ou dela).

Assim, o Senderel femininizado de Mendele parece estar muito bem encaixado nos objetivos do autor em condenar a mentalidade dos judeus do Leste Europeu, uma mentalidade que os impedia de ver o potencial para a regeneração cultural e física. O par com o delgado Benjamin fornece, ainda, dentro do modelo dado por Cervantes, uma resposta que coloca estes personagens à parte de todos os outros judeus. Eles não são representativos, são anomalias, parte do mundo paródico no qual o corpo judeu pode ser exposto porque o Haskalah oferece um modo pelo qual ele pode ser reformado. Mas a relação especial do corpo obeso com o homem feminizado aqui é usada para refutar a hipótese do menino gordo "oriental" que assombra a imagem do judeu no Ocidente. Este par de anti-heróis emprega o "amigo gordo" como um meio de caracterizar relações entre homens e, desta forma, definir a masculinidade. A figura literária e os relatos autobiográficos são recortados do mesmo tecido cultural. Aqui as ligações com as imagens pós-paulinas da decadência do corpo, especificamente do corpo judeu, que assombra o Iluminismo francês, são refletidas em sua inclusão nas afirmações do

${ }^{41}$ JeLLINEK, A. Der jüdische Stamm: Ethnographische Studien. Vienna, Herzfeld und Bauer, 1869, pp.89-90. 
Iluminismo iídiche e sua primeira imagem literária do judeu gordo. Assim, a obesidade se torna um meio de crítica social interna em uma era em que a imagem do corpo do judeu como oriental, portanto, doente, era central para os debates sobre raça $e$ obesidade. O mundo da ficção do Iluminismo ecoa a mudança no significado do corpo sob o cristianismo e seus sucessores seculares, científicos, no século XIX.

$\mathrm{Na}$ história da imagem do judeu obeso, podemos observar como a imagem do dano, tão importante para as definições de deficiência, torna-se parte de uma crítica externa assim como interna da própria noção de deficiência física. Ela é algo intrínseco ou pode ser alterado e mudado? Isto está no centro da leitura ideológica da "raça" nos debates sobre corpos judeus na era moderna. A deficiência se torna um modo de redefinir a natureza da identidade judaica como "sob risco" e, portanto, incapaz de funcionar no mundo. Alguém pode mudar a natureza do corpo judeu? Certamente os iluministas judeus e depois os sionistas pensaram que este seria um primeiro passo necessário à verdadeira emancipação. Os especialistas em obesidade $e$ diabetes tenderam a imaginar o corpo judeu sob risco com várias possibilidades para mudança. Mas permaneceu em todas estas representações a percepção de que havia algo na "essência" do judeu que era diferente e anormal. O corpo obeso representou esta diferença de modos complexos e freqüentemente contraditórios. 